\section{Commentary: Management of chyloptysis: What tools are in your toolbox?}

\author{
Taryne A. Imai, MD
}

Chyloptysis is a rare clinical entity, presenting with diagnostic perplexity and challenges in treatment. It has been described in only a few case reports in the literature and is associated with lymphatic agenesis and malformations, lymphangiomatosis, yellow nail syndrome, Behçet disease, radiation, malignancy, and trauma. ${ }^{1-4}$ Although a variety of sputum analyses have been reported to confirm the diagnosis of chyloptysis, lymphangiography is regarded as the recommended diagnostic test. ${ }^{5}$ Multiple mechanisms have been proposed to explain the introduction of chyle into the airways. In the setting of trauma, chyloptysis may be due to disruption of the thoracic duct or mediastinal lymphatics with subsequent development of a broncholymphatic fistula. It often presents soon after the inciting traumatic event; however, in the case report by Mitchell and colleagues, ${ }^{6}$ they describe a delayed presentation in a patient who sustained a left flank stab wound more than a decade before the onset of chyloptysis. In addition to their comprehensive clinical review, they detail their successful management of chyloptysis by using a right thoracoscopic approach for thoracic duct ligation.

Similar to other published case reports on chyloptysis, perhaps the most impactful value of the report by Mitchell and colleagues ${ }^{6}$ is the knowledge-sharing of different strategies used to treat this challenging and rare clinical entity. Initial strategies often implement a trial of

\footnotetext{
From the Division of Thoracic Surgery, Department of Surgery, Cedars-Sinai Medical Center, Los Angeles, Calif.

Disclosures: The author reported no conflicts of interest.

The Journal policy requires editors and reviewers to disclose conflicts of interest and to decline handling or reviewing manuscripts for which they may have a conflict of interest. The editors and reviewers of this article have no conflicts of interest.

Received for publication July 27, 2021; revisions received July 27, 2021; accepted for publication July 30, 2021; available ahead of print Aug 5, 2021.

Address for reprints: Taryne A. Imai, MD, Division of Thoracic Surgery, Department of Surgery, 8631 W 3rd St, East Tower, Suite 240E, Los Angeles, CA 90048 (E-mail: Taryne.Imai@cshs.org).

JTCVS Techniques 2021;9:183-4

2666-2507

Copyright (C) 2021 The Author(s). Published by Elsevier Inc. on behalf of The American Association for Thoracic Surgery. This is an open access article under the CC BY-NC-ND license (http://creativecommons.org/licenses/by-nc-nd/4.0/).

https://doi.org/10.1016/j.xjtc.2021.07.025
}

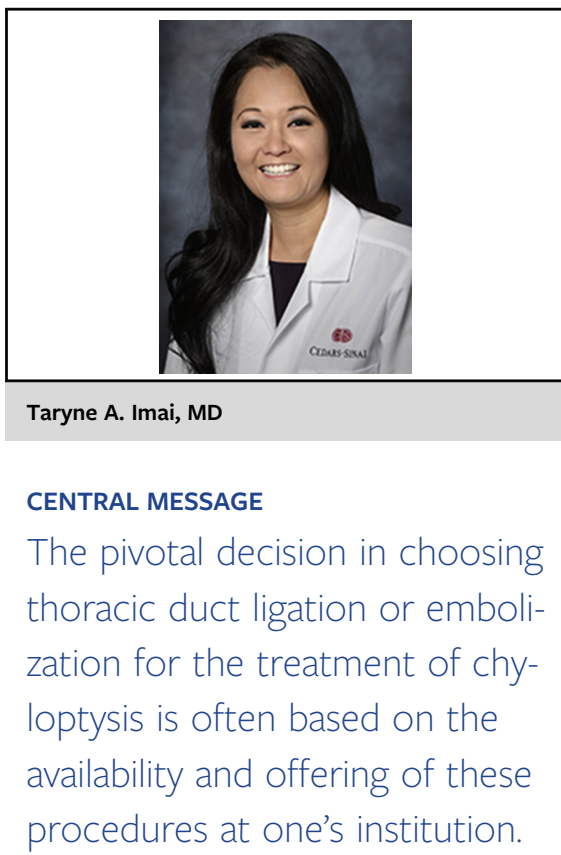

conservative management with a low-fat or mediumchain triglyceride diet, sometimes with an octreotide adjunct to further reduce lymphatic flow. Patients who have persistent chyloptysis despite diet modifications are then recommended to undergo either surgical or percutaneous management. Surgical management primarily consists of thoracic duct ligation with an open or thoracoscopic approach and has success rates ranging from $67 \%$ to $100 \%{ }^{7}$ Alternatively, the thoracic duct can be visualized with lymphangiography and percutaneously embolized with coils, liquid embolic agents, or a combination of both. ${ }^{5}$ Reported success rates of embolization range from $71 \%$ to $73.5 \%{ }^{8}$

Whether one approach to treatment is preferred or superior has yet to be determined. Surgical thoracic duct ligation is highly successful, as it directly stops lymphatic flow; however, it necessitates a period of postoperative recovery. Although thoracoscopic approaches have become more common, allowing for quicker recovery, the procedure is still associated with risks of operative and anesthesia morbidity. ${ }^{2,7}$ Embolization, with comparative success rates, has lower risks due to the ability of performing the procedure under local anesthetic and sedation, therefore avoiding general anesthesia and single-lung ventilation. However, the success rates of embolization are determined by the 
ability to visualize the cisterna chyli or the thoracic duct and catheterize it, which are dependent on the body habitus of the patient and operator experience.

Despite head-to-head comparisons and weighing the pros and cons of each procedure, in most institutions, the pivotal decision of how to treat chyloptysis is not based on clinical data or patient selection but often driven by the availability of the procedure at one's institution. Since both treatments are not routine procedures, institutions may not have a surgeon on staff experienced in thoracoscopic thoracic duct ligation or an interventionalist facile in thoracic duct cannulation and embolization. Therefore, although it continues to be debated as to which treatment for chyloptysis is more successful, ultimately the final treatment decision will likely be determined by the resources or tools available or offered in your institution's toolbox.

\section{References}

1. Lim KG, Rosenow EC, Staats B, Couture C, Morgenthaler TI. Chyloptysis in adults: presentation, recognition, and differential diagnosis. Chest. 2004;125:336-40.

2. Xu RB, Crouch G, Jurisevic C, Stuklis RG. Right video-assisted thoracoscopy thoracic duct ligation as treatment for a case of chyloptysis. J Thorac Cardiovasc Surg. 2013;145:e64-5.

3. Kato S, Umezawa H, Yano T, Ogasawara T, Kasamatsu N, Hashizume I. Chyloptysis after ligation of the thoracic duct. Intern Med. 2012;51:2403-6.

4. Gillaspie EA, Lim K, Nichols FC. Surgical management of chyloptysis. Ann Thorac Surg. 2018;105:e79-81.

5. Chick JF, Nadolski GJ, Lanfranco AR, Haas A, Itkin M. Dynamic contrastenhanced magnetic resonance lymphangiography and percutaneous lymphatic embolization for the diagnosis and treatment of recurrent chyloptysis. J Vasc Interv Radiol. 2019;30:1135-9.

6. Mitchell KG, Feldman H, Meyers BF, Antonoff MB. Chyloptysis as a delayed sequela of penetrating thoracic trauma. J Thorac Cardiovasc Surg Tech. 2021;9: $180-2$.

7. Bender B, Murthy V, Chamberlain RS. The changing management of chylothorax in the modern era. Eur J Cardiothorac Surg. 2016;49:18-24.

8. Itkin M, Kucharczuk JC, Kwak A, Trerotola SO, Kaiser LR. Nonoperative thoracic duct embolization for traumatic thoracic duct leak: experience in 109 patients. $J$ Thorac Cardiovasc Surg. 2010;139:584-90. 